\title{
Conjoint influence of mind-wandering and sleepiness on task performance
}

David Stawarczyk and Arnaud D’Argembeau

University of Liège

Author Note

David Stawarczyk and Arnaud D’Argembeau, Department of Psychology, Psychology and Neuroscience of Cognition Research Unit, University of Liège, Liège, Belgium.

David Stawarczyk and Arnaud D'Argembeau are supported by the Fund for Scientific Research (FRS-FNRS), Belgium.

We would like to thank Cindy Brandt and Philippe Niessen for their help in collecting the data.

Correspondence concerning this article should be addressed to David Stawarczyk, Department of Psychology, University of Liège, Quartier Agora, place des Orateurs 1, 4000 Liège 1. E-mail: d.stawarczyk@ulg.ac.be 


\begin{abstract}
Recent research suggests that sleepiness and mind-wandering-the experience of thoughts that are both stimulus-independent and task-unrelated-frequently co-occur and are both associated with poorer cognitive functioning. Whether these two phenomena have distinguishable effects on task performance remains unknown, however. To investigate this question, we employed the online experience sampling of mind-wandering episodes and subjective sleepiness during a laboratory task (the Sustained Attention to Response Task; SART), and also assessed mind-wandering frequency and sleep-related disturbances in daily life using self-report questionnaires. The results revealed that the tendency to experience mind-wandering episodes during the SART and daily life was associated with higher levels of daytime sleepiness and sleep-related disturbances. Importantly, however, mind-wandering and sleepiness were independent predictors of SART performance at both the within- and between-individuals levels. These findings demonstrate that, although mind-wandering and sleepiness frequently co-occur, these two phenomena have distinguishable and additive effects on task performance.
\end{abstract}

Key words: mind-wandering; daytime sleepiness; sleep-related disturbances; sustained attention to response task; attentional abilities 


\section{Introduction}

While performing daily activities like driving to work, washing the dishes, or listening to lectures, our mind frequently drifts away from the current task at hand and focuses instead on internal thoughts that are unrelated to the present situation, such as memories, personal concerns, or thoughts about future events. This kind of experience is generally referred to as mind-wandering and can be more precisely defined as the occurrence of self-generated thoughts that are both unrelated to the current task at hand (i.e., they are task-unrelated) and decoupled from immediate sensory perceptions (i.e., they are stimulus-independent; Singer, 1993; Smallwood \& Schooler, 2006; Smallwood \& Schooler, 2015; Stawarczyk, Majerus, Maj, Van der Linden, \& D'Argembeau, 2011). Recent experience-sampling studies have shown that mind-wandering represents from 30 to $50 \%$ of our daily cognitive functioning and is pervasive during nearly all kinds of tasks and activities (Kane, Brown, et al., 2007; Killingsworth \& Gilbert, 2010), which may explain the growing theoretical and empirical attention that has been devoted to this phenomenon during the last decade (Callard, Smallwood, Golchert, \& Margulies, 2013).

Although mind-wandering may be beneficial in some respects, for instance by allowing oneself to plan and remember things that need to be done in the future (e.g., Baird, Smallwood, \& Schooler, 2011; Mason \& Reinholtz, 2015; Stawarczyk, Cassol, \& D'Argembeau, 2013; Stawarczyk \& D'Argembeau, 2015; Stawarczyk, Majerus, Maj, et al., 2011), to generate creative ideas (Baird et al., 2012; Singer \& McCraven, 1961; Singer \& Schonbar, 1961), and to display more patience for future rewards (Bernhardt et al., 2014; Smallwood, Ruby, \& Singer, 2013), a major negative consequence of this mental state is that it is generally detrimental to the task being performed at the moment of its appearance (for a meta-analysis, see Randall, Oswald, \& Beier, 2014). For instance, in laboratory studies, mindwandering has been consistently associated with decreased text comprehension while reading 
(e.g., Schooler, Reichle, \& Halpern, 2004; Smallwood, 2011), with poorer memory encoding (e.g., Maillet \& Rajah, 2013; Mrazek et al., 2012; Smallwood, Baracaia, Lowe, \& Obonsawin, 2003), and with more errors and variable response times (RTs) during attentional tasks (e.g., McVay \& Kane, 2009, 2012; Stawarczyk, Majerus, Catale, \& D'Argembeau, 2014).

Studies that used more ecological daily life inquiries have also shown that mindwandering impairs activities such as driving (e.g., Galera et al., 2012; He, Becic, Lee, \& McCarley, 2011; Qu et al., 2015; Yanko \& Spalek, 2014), piloting planes (Casner \& Schooler, 2014, 2015), and memorizing information presented during classroom lectures (e.g., Farley, Risko, \& Kingstone, 2013; Risko, Anderson, Sarwal, Engelhardt, \& Kingstone, 2012; Szpunar, Moulton, \& Schacter, 2013), which may directly impact the final course grades obtained by college students (Lindquist \& McLean, 2011), as well as their Graduate Record Examination (GRE; Mrazek, Franklin, Phillips, Baird, \& Schooler, 2013) and Scholastic Assessment Test (SAT) scores (Unsworth, Brewer, \& Spillers, 2012; Unsworth, McMillan, Brewer, \& Spillers, 2012), two of the most common standardized tests of academic abilities employed in the United States of America.

Importantly, mind-wandering is not the only commonly experienced phenomenon that has deleterious impacts on task performance and daily life activities. Fatigue and daytime sleepiness resulting from inadequate sleep duration and sleep disturbances are extremely frequent, particularly in young adults and college students (Hershner \& Chervin, 2014). Recent cohort studies indeed suggest that it may affect around 15 to $25 \%$ of individuals in these populations (e.g., Ford, Cunningham, Giles, \& Croft, 2015; Taylor, Bramoweth, Grieser, Tatum, \& Roane, 2013), with approximately $70 \%$ of college students reporting less than the recommended eight hours of sleep per night (Lund, Reider, Whiting, \& Prichard, 2010). Strikingly, sleepiness seems to have similar effects as mind-wandering on a wide range of tasks with, for instance, extensive evidence indicating that learning and memory encoding 
are impaired during periods of sleep deprivation or restriction, and that increased sleepiness results in impaired RTs and lower accuracy during attentional tasks (for recent reviews, see Jackson \& Van Dongen, 2011; Killgore, 2010; Lim \& Dinges, 2008; Short \& Banks, 2014). In addition, sleepiness is recognized as a major cause of driving accidents (e.g., Connor et al., 2002; Garbarino, Nobili, Beelke, De Carli, \& Ferrillo, 2001; MacLean, Davies, \& Thiele, 2003) and poorer academic performance (e.g., Curcio, Ferrara, \& De Gennaro, 2006; Gaultney, 2010; Gomes, Tavares, \& de Azevedo, 2011).

The above mentioned findings indicate that mind-wandering and sleepiness have a similar deleterious impact on cognitive functioning. Few studies investigated whether these two phenomena are related, however. Some studies that sampled mind-wandering in daily life (McVay, Kane, \& Kwapil, 2009) or during laboratory tasks (Ottaviani, Shapiro, \& Couyoumdjian, 2013) suggest that mind-wandering episodes are associated with higher levels of tiredness. Furthermore, recent studies found that a higher frequency of self-reported mindwandering was associated with poorer sleep quality and more daytime sleepiness (Carciofo, Du, Song, \& Zhang, 2014), and that negatively valenced intrusive thoughts sampled during daytime could be predicted by retrospective self-reports of sleep-related difficulties during the past month (Baker, Baldwin, \& Garner, 2015). However, another study that sampled mindwandering in daily life found no association with self-reported arousal (Song \& Wang, 2012). Apart from this latter study, preliminary results thus suggest that the frequency of mindwandering episodes increases with daytime sleepiness and sleep disturbances in daily life. However, none of these studies examined the respective influence of mind-wandering and sleepiness on task performance. This question is particularly important because, as mindwandering and daytime sleepiness seem to frequently co-occur, it could be that the negative effects that have been previously associated with mind-wandering result from sleepiness 
rather than mind-wandering per se (or, inversely, that the adverse effects of daytime sleepiness result, at least in part, from the concomitant presence of mind-wandering episodes).

To investigate this possibility in the present study, we examined the relationships between mind-wandering and sleepiness during a laboratory task (with the online experience sampling of mind-wandering episodes and sleepiness during a computerized attentional task), and also collected estimates of mind-wandering frequency and sleep-related disturbances in everyday life (using retrospective self-report questionnaires). To assess the respective impact of mind-wandering and sleepiness on task performance, we more specifically used the Sustained Attention to Response Task (SART; Robertson, Manly, Andrade, Baddeley, \& Yiend, 1997) in which we embedded thought-probes (Smallwood \& Schooler, 2006) and the Karolinska Sleepiness Scale (KSS; Akerstedt \& Gillberg, 1990), a highly validated and reliable one-item scale that is frequently used as a proxy of physiological and behavioral indicators of sleepiness (Kaida et al., 2006). The SART is one of the most commonly used task to assess the behavioral (e.g., McVay \& Kane, 2012; Smallwood et al., 2004; Stawarczyk et al., 2014; Stawarczyk, Majerus, Maj, et al., 2011) and neural (e.g., Christoff, Gordon, Smallwood, Schooler, \& Smith, 2009; Stawarczyk, Majerus, Maquet, \& D'Argembeau, 2011) correlates of mind-wandering ${ }^{1}$. This task is also sensitive to decreases in performance associated with increased sleepiness resulting, for instance, from sleep deprivation and restriction (e.g., Gabel et al., 2013; Lo et al., 2012) or wake duration (e.g., Harrison, Jones, \& Waterhouse, 2007). Overall, this study allowed us to examine (1) whether the presence of mind-wandering in daily life and during the SART is associated with higher levels of sleepiness and sleep-related disturbances, and (2) to what extent mind-wandering and sleepiness have distinguishable effects on the behavioral markers of SART performance (i.e., accuracy to the target stimuli, as well as the mean and coefficient of variation of RTs to the non-target stimuli) at both the between- and within-individual levels. 


\section{Methods}

\section{Participants}

A total of 95 French-speaking participants (66 women) from the Belgian general population volunteered to participate in the study, most of which were either undergraduates or graduate students at the University of Liège, Belgium. This sample size was determined a priori using G*Power 3 (Faul, Erdfelder, Lang, \& Buchner, 2007) in order to achieve 80\% power, considering an alpha error of .05 and a medium effect size for between-participants multiple regression and correlations analyses $\left(r=.30\right.$ and $\mathrm{R}^{2}=.10$; see also Green, 1991). This sample size is also adequate to obtain accurate estimates of the regression coefficients, variance components, and standard errors in the multilevel regression analyses that we performed to investigate within-individual effects (Maas \& Hox, 2005; see below). The mean age of the participants was 23.45 years $(S D=2.45$; range $=19-35$ years $)$ with a mean of 3.97 successful years of higher education $(S D=2.09$; range $=0-11$ years $)$. Individuals with delayed sleep schedules (e.g., shift workers) or suffering from medical, neurological, or psychiatric disorders were not included in the study. The mean subjective sleep duration reported by our participants in the seven days preceding the testing session was 7.15 hours $(S D=1.10$; range $=3.50-9.25$ hours $)$. This duration is similar to the usual sleep length reported by college students in western populations (e.g., Lund et al., 2010).

\section{Task and questionnaires}

SART with embedded thought-probes and KSS. Participants carried out an adaptation of the SART with thought-probes previously used in Stawarczyk, Majerus, Maj, et al. (2011). Participants were presented with numbers comprised between 1 and 9 that appeared sequentially in the center of a laptop computer screen. They were instructed to respond as fast and accurately as possible to each number (i.e., the non-target stimuli) by 
pressing the spacebar on the keyboard, except when presented with the number 3 (i.e., the target stimulus; $11 \%$ of probability of appearance) for which they were told to withhold their response. Each stimulus was presented in white font (Arial with a point size of 72) on a black background for $500 \mathrm{~ms}$ with an interstimulus interval of $2000 \mathrm{~ms}$. The task consisted in 28 blocks of either $35,45,55$, or $65 \mathrm{~s}$ (seven blocks of each length presented in a determined pseudorandom order) and the last five stimuli of each block were always non-targets. 560 numbers were presented in total.

Each block was immediately followed by the KSS (Akerstedt \& Gillberg, 1990), which interrupted the task and asked participants how they felt right before the interruption. The KSS is a measure of subjective sleepiness that consists in a 9-point Likert scale ranging from 1 = completely alert to $9=$ very sleepy, great effort to keep awake. Previous studies that embedded the KSS within vigilance tasks have shown that this scale is sensitive to behavioral indicators of sleepiness and to the increase of sleepiness with time on task (Kaida, Akerstedt, Kecklund, Nilsson, \& Axelsson, 2007b) and that the repeated administrations of this scale have only minimal impact on the carrying out of the tasks and on the physiological markers of sleepiness (Kaida, Akerstedt, Kecklund, Nilsson, \& Axelsson, 2007a).

Immediately after the KSS, participants were asked to characterize the ongoing conscious experience they had just prior the interruption (Stawarczyk, Majerus, Maj, et al., 2011). Five possibilities were provided: (i) on-task: the participant's attention and thoughts were fully focused on the task-related stimuli; (ii) task-related interference: the participant experienced thoughts about some task features or about their performance (e.g., thoughts about task duration or about the participant's overall performance). Participants were explained that this category comprised all thoughts about the task that did not help them to respond as fast and accurately as possible to the numbers presented on the screen. The third category was (iii) external distraction: the participant's attention was focused on stimuli that 
were present in the current environment but unrelated to the task at hand (e.g., exteroceptive perceptions or interoceptive sensations). It was explained to the participants that this category comprised all thoughts whose content was directly focused on current sensory perceptions unrelated to the task at hand, with the origin of these perceptions being either external (e.g., coming from the room) or internal (e.g. bodily sensations). The fourth category was (iv) mind-wandering: the participant had his/her attention decoupled from the current environment and was experiencing thoughts unrelated to the task at hand (e.g., thoughts about what the participant will do later in the day). Finally, the last category was (v) absence: the participant's attention was not focused on the task at hand and he/she was not thinking about anything in particular, meaning that his/her mind was blank (e.g., Andrews-Hanna, Reidler, Huang, \& Buckner, 2010; Ward \& Wegner, 2013).

After each thought probe, a short text was displayed on the screen that asked participants to press the spacebar to continue the task. When participants provided a mindwandering report, the text display additionally reminded them to write down a description of the thought they were experiencing before pressing the spacebar to resume the task. Participants were told that their descriptions should be detailed enough to allow them to clearly remember (after the task) what they were thinking about and that they could describe their thoughts by noting down key-words if they wanted. No mention was made about the Thought Characteristics Questionnaires (see below) at this point of the task. In the present study, the KSS was always administered before the thought probes in order to prevent differences between conditions in the delay between task interruption and ratings (because participants had to describe their mind-wandering experiences, administrating the though probe first would have delayed KSS ratings when participants report mind-wandering compared to other response categories). 
Similarly to our previous studies (e.g., Stawarczyk et al., 2014; Stawarczyk, Majerus, Maj, et al., 2011), several examples reflecting each kind of response to the thought probes were provided to the participants and they were asked to classify 10 thoughts in the adequate categories before the beginning of the SART. They also carried out two training blocks before starting the complete task and were given a written summary of the instructions to help them in case of doubt when responding to the thought probes.

Thought Characteristics Questionnaire (TCQ). The content and characteristics of each mind-wandering episode reported during the SART were assessed with a self-report questionnaire adapted from Stawarczyk, Majerus, Maj, et al. (2011). For each mindwandering episode, the following phenomenological dimensions were assessed with sevenpoint Likert scales: (1) the thought involved visual imagery $(1=$ not at all, $7=$ totally $),(2)$ the thought involved inner speech $(1=$ not at all, $7=$ totally $)$, (3) the occurrence of the thought was intended and intentional (i.e., the participant intentionally decided to think of something else than the SART; $1=$ not at all, 7 = totally), (4) the thought belonged to a structured succession of thoughts (such as in reasoning, reflection or argumentation; $1=$ not at all, $7=$ totally), (5) the content of the thought was realistic/plausible and related to something concrete and well-defined (e.g., a precise situation or a particular action; $1=$ not at all, $7=$ totally), (6) the content of the thought was of importance to the participant's life (e.g., related to the participant's personal goals and projects; $1=$ not at all, $7=$ totally), (7) the thought often comes to the participant's mind in daily life $(1=$ never, $7=$ very often $)$, and $(8)$ the affective valence of the thought's content $(-3=$ very negative, $+3=$ very positive $)$.

In addition to these phenomenological dimensions, participants were also asked to characterize each mind-wandering episode according to its temporal orientation by choosing between: (1) past, (2) present, (3) future or (4) no precise temporal orientation. For past and future mind-wandering episodes, participants were also asked to specify the temporal distance 
of their thoughts by choosing between six different categories: (1) before/later in the present day, (2) between yesterday/tomorrow and the past/next seven days, (3) between one week and one month in the past/future, (4) between one month and one year in the past/future, (5) more than one year away in the past/future, and (6) no precise temporal distance. Finally, subjects were asked to specify the main function of each thought by choosing between: (1) to make a decision/solve a problem, (2) to plan something, (3) to reappraise a situation, (4) to feel better, (5) to help stay awake/alert, (6) another unlisted function (in which case, participants were asked to specify what the function was), and (7) daydream with no apparent function.

Insomnia Severity Index (ISI). The ISI (French version by Blais, Gendron, Mimeault, \& Morin, 1997; original scale by Morin, 1993) was used to evaluate sleep difficulties and their possible consequences on daytime activities. The ISI contains seven items that are rated on a five-point Likert scale ranging from 0 to 4 . The wording of the response options differs among the items but higher ratings always correspond to higher sleep-related difficulties. Respondents are asked to rate for the last month (i) the severity of their insomnia (difficulty falling asleep, difficulty staying asleep, problem waking up too early); (ii) their satisfaction with their current sleep patterns; (iii) the interference that their sleep difficulties have on daytime functioning; (iv) the noticeability of their sleep-related impairments to significant others; and (v) the level of distress caused by their sleep problems. The internal consistency of this scale in the present sample was $\alpha=.85$.

Daydreaming Frequency Scale (DDFS). The DDFS (original scale by Singer \& Antrobus, 1970; French version by Stawarczyk, Majerus, Van der Linden, \& D'Argembeau, 2012) was used to evaluate the general tendency of the participants to mind-wander in daily life. The DDFS consists in 12 items that are rated on a five-point Likert scale ranging from A to E. The wording of the response options to which the letters correspond differs among the items but the higher placed letters in the alphabetical order always correspond to an increased 
experience of mind-wandering in daily life. Values of $1,2,3,4$, or 5 were assigned to the options depending on their ordinal position on the continuum. The internal consistency of this scale in the present sample was $\alpha=.92$.

\section{Procedure}

Participants were tested individually in the presence of the experimenter in a quiet and well-lighted room. Participants first completed an informed consent form and responded to demographic questions as well as a short anamnesis. They then completed the ISI and questions regarding their sleep in the past week before carrying out the SART with embedded thought-probes and KSS. Directly after the SART, participants rated each of their reported mind-wandering episodes on the TCQ and then completed the DDFS. Participants also completed a series of other self-report questionnaires at the end of the testing session that are not reported here because they are not directly relevant to aims of the present study. In total, the testing session lasted around 60 to $75 \mathrm{~min}$.

\section{Results}

We first performed between-participant correlation analyses using data from both retrospective questionnaires of daily life experiences and online measures made during the SART to examine whether levels of sleepiness and sleep-related disturbances are related to the frequency of mind-wandering. Second, we performed multiple regression analyses (also at the between-participants level) to examine whether individual differences in sleepiness and mind-wandering are independent predictors of SART performance as measured by response accuracy to the target stimuli, as well as the mean and coefficient of variation (i.e., $\sigma / \mu^{*} 100$ ) of RTs to the non-target stimuli, for the whole task. Third, we performed within-participant analyses to examine whether variations in the level of sleepiness across blocks during the 
SART are related to variations in task performance and mind-wandering. More specifically, we conducted regression analyses to examine (1) whether the different kinds of reports made to the thought probes during the SART are associated with different levels of sleepiness, (2) whether self-reports of increased sleepiness are related to decreases in task performance, and (3) whether such decreases are distinguishable from the performance decrement associated with mind-wandering episodes. In these latter analyses, target accuracy was measured for each block and, considering recent findings showing that mind-wandering is associated with abrupt fluctuations in RTs lasting between 2.5 and 10 seconds (Henriquez, Chica, Billeke, \& Bartolomeo, 2016), the mean and CV of RTs were computed for the last four targets of each block (corresponding to a 10-second period). Finally, at a more exploratory level, we also examined whether mind-wandering episodes reported under high levels of sleepiness have different phenomenological properties than episodes reported when participants feel more awake.

\section{Between-participant correlation analyses}

The intercorrelations between all variables across participants, as well as means and standard deviations, are shown in Table 1. As expected, the ISI, KSS, DDFS, and frequency of mind-wandering reports to the thought probes were all significantly related to each other. These results indicate that sleep-related disturbances are related to higher frequency of mindwandering in daily life, and that the degree of sleepiness and frequency of mind-wandering episodes while performing the SART are also related to each other.

Concerning the relationships between mind-wandering, sleepiness, and SART performance, our analyses showed the expected results that mind-wandering reports and ratings of somnolence (KSS) during the SART were both related to commission errors to the target stimuli and increased RT variability. Sleep-related difficulties in daily life (ISI) were 
also related to a higher number of commission errors and increased RT variability, whereas the frequency of mind-wandering in daily life (DDFS) was unrelated to SART performance. Very low correlations $(r s<.10)$ were found between mean RTs to the non-target stimuli and measures of mind-wandering and sleepiness/sleep-related difficulties.

With regard to the other kinds of responses to the thought-probes, it can be noted that reports of being fully focused on task were related to better SART performance (higher target accuracy and lower RT variability) and lower sleepiness scores on the KSS. The other three categories of responses to the thought-probes (task-related interferences, external distractions, and absences) were not consistently related to the indices of SART performance and sleepiness/sleep-related disturbances, with the exception of absences that showed a moderate and positive relationship with the KSS ratings.

\section{Conjoint influence of mind-wandering and sleepiness on SART performance at the between-participant level}

As expected, the correlational analyses showed that mind-wandering frequency and sleepiness during the SART were both related to task performance. We thus conducted multiple regression analyses to determine whether mind-wandering and sleepiness are independent predictors of target accuracy and RT variability during the SART. We first examined whether the KSS ratings and frequency of mind-wandering reports were independent predictors of the variability of RTs. The results showed that the total regression model was significant $\left[F(2,92)=6.74 ; p=.002 ; R^{2}=.13\right]$, and that both sleepiness and mindwandering frequency uniquely predicted the coefficient of variation of RTs to the non-target stimuli (see Table 2). More specifically, out of the $12.77 \%$ of the variance of RT variability explained by the two independent variables, $3.85 \%$ was shared between the KSS and mind- 
wandering reports, $5.24 \%$ was specific to mind-wandering, and $3.68 \%$ was specific to the KSS.

Next, we conducted multiple regression models with accuracy to the target stimuli during the SART as dependent variable. Numerous previous studies have found that, at the between-individuals level, errors to the target stimuli during the SART are highly influenced by intentional speed-accuracy trade-offs performed by the participants (i.e., deliberately slowing down RTs to the non-target stimuli to increase accuracy to the target stimuli, see Helton, 2009; Helton, Kern, \& Walker, 2009; Seli, Cheyne, \& Smilek, 2012), and it has been strongly suggested to control for the effect of non-target RTs when examining the betweenparticipant relationships between SART accuracy and other attentional variables (Seli, Jonker, Cheyne, \& Smilek, 2013). In the present research, we found a strong positive correlation between mean RTs to the non-targets and target accuracy $(r=.485$, see Table 1$)$, suggesting that our participants did indeed engage in this kind of deliberate speed-accuracy trade-off. We therefore added mean RTs to the non-target stimuli as an additional independent variable besides the KSS ratings and mind-wandering reports. This regression model was significant $\left[F(3,91)=15.56 ; p<.001 ; R^{2}=.34\right]$ and, again, both mind-wandering frequency and sleepiness were independent predictors of target accuracy (see Table 2). More specifically, out of the $10.39 \%$ of the variance of SART accuracy that was explained by mind-wandering and KSS scores above and beyond the effect of mean RTs, $3.11 \%$ were common to these two independent variables, $3.50 \%$ were specific to mind-wandering reports, and $3.78 \%$ were specific to the KSS scores ${ }^{2}$. 


\section{Within-participant variations in sleepiness during the SART and their relationships with thought-probe responses and task performance}

To examine whether sleepiness increased with time on task, we conducted a one-way repeated measures ANOVA with KSS ratings reported during the SART as dependent variables. As shown in Figure 1, there was a significant effect of time on task, indicating an increase in sleepiness with successive KSS administrations $\left[F(27,2538)=43.23 ; p<.001 ; \eta_{p}^{2}\right.$ $=.32]$. This increase in sleepiness is similar to what has been observed in previous studies that administered the KSS before and after relatively long (around $40 \mathrm{~min}$ ) versions of the SART; those studies also found a mean increase of approximately three points on the KSS after performing the task (e.g., Bonnefond, Doignon-Camus, Touzalin-Chretien, \& Dufour, 2010).

Next, we sought to examine whether sleepiness was related to the kind of response given by the participants to the thought probes. Due to the hierarchical structure of the data, we used multilevel statistical modeling (with reports as level 1 units and participants as level 2 units; see e.g., Hox, 2010) and fitted the data from the 2660 thought-probes (which are nested within the 95 participants) to a random intercept multilevel model using MLwiN (Rasbash, Charlton, Browne, Healy, \& Cameron, 2009). The KSS was the dependent variable and the kind of experience reported to the thought probes was the explanatory variable (with reports of being focused on task used as the reference category). Our analyses first showed that $42 \%$ of the total variance of the KSS scores was due to within-participant differences. A likelihood ratio $(\mathrm{LR})$ test revealed a significant effect of thought-probe responses $[L R(1 \mathrm{df})=$ 345.99; $p<.001]$, indicating that sleepiness varied between the different categories of reported experiences. We next examined more specifically whether each kind of response to the thought probes differed from being fully focused on task. Results showed that mindwandering, absences, external distractions, and task-related interferences were all associated with higher levels of sleepiness compared to being fully focused on task (see Table 3 and 
Figure 2). Finally, we computed Wald tests to contrast the level of sleepiness associated with mind-wandering to the other categories. These analyses showed that mind-wandering episodes were associated with more sleepiness than task-related interferences (Wald $\chi^{2}=$ 19.81; $\mathrm{df}=1 ; p<.001$ ), less sleepiness than absences (Wald $\chi^{2}=33.37 ; \mathrm{df}=1 ; p<.001$ ), and did not differ from external distractions (Wald $\chi^{2}=1.46 ; \mathrm{df}=1 ; p=.23$ ).

We also examined whether SART performance in each block varied according to sleepiness and responses to the thought probes, and whether these two variables were independent predictors of task performance. To do so, we fitted random intercept multilevel models with percentage of accuracy to the target stimuli, coefficient of variation to the nontarget stimuli, or mean RTs to the non-target stimuli as dependent variable. Target accuracy was measured for the whole block, and the mean and CV of RTs were computed for the 10second period preceding the end of each block (Henriquez et al., 2016) ${ }^{3}$. For each dependent variable, we first fitted a multilevel model that only included sleepiness as dependent variable, and then fitted a model in which sleepiness and responses to the thought probes were considered simultaneously. For the models including responses to the thought probes as explanatory variable, reports of being fully focused on task were used as the reference category.

With regard to target accuracy, $77 \%$ of the total variance was due to within-participant differences. A LR test for the first model with sleepiness alone as independent variable indicated that target accuracy was lower with increasing level of sleepiness $[b=-4.74(S E=$ 0.43); $L R(1 \mathrm{df})=119.77 ; p<.001]$. The LR test for the model with sleepiness and thought probe responses considered simultaneously revealed that this second model explained a significantly larger part of the variance of target accuracy than the model with sleepiness considered alone $[L R(1 \mathrm{df})=84.685 ; p<.001]$. Furthermore, the coefficients of both sleepiness and each of the four kinds of response to the thought probes were significant (see 
Table 4), indicating that these different variables have (at least partially) independent influences on target accuracy.

With regard to the coefficient of variation of RTs, $89 \%$ of the total variance was due to within-participant differences. The LR test for the first model with sleepiness alone as independent variable indicated that RT variability was higher with increasing level of sleepiness $[b=0.55(S E=0.11) ; L R(1 \mathrm{df})=23.94 ; p<.001]$. The LR test for the model with sleepiness and thought-probe responses considered simultaneously indicated that this second model explained a significantly larger part of the variance of RT variability than the model with sleepiness considered alone $[L R(1 \mathrm{df})=12.68 ; p<.001]$. The coefficients for sleepiness, task-related interference, external distractions, and mind-wandering were significant in this second model (see Table 5), indicating that these different variables all have (at least partially) independent influences on RT variability.

Finally, concerning the mean RTs, $57 \%$ of the total variance was due to withinparticipant differences. The LR test for the first model with sleepiness alone as independent variable indicated that RTs were faster with increasing level of sleepiness $[b=-2.57$ ( $S E=$ $0.65) ; L R(1 \mathrm{df})=15.51 ; p<.001]$. The LR test for the model with sleepiness and thoughtprobe responses considered simultaneously indicated that this second model explained a significantly larger part of the variance of mean RTs than the model with sleepiness only $[L R$ $(1 \mathrm{df})=8.02 ; p=.005]$. Interestingly, in this last model, sleepiness remained associated with faster RTs, whereas mind-wandering and EDs were also significant predictors but were associated with slower RTs compared to being fully focused on task (see Table 6). These results suggest that mind-wandering and sleepiness have opposite effects on the speed of RTs to non-target stimuli during the SART at the within-participants level. 


\section{Sleepiness and the phenomenology of mind-wandering}

Finally, we examined the possibility that sleepiness may vary according to the phenomenological properties of the reported mind-wandering episodes. To do so, we fitted a random intercept multilevel model with KSS ratings as dependent variable and the index of the phenomenological dimensions of the 409 mind-wandering episodes as explanatory variables. We first examined whether mind-wandering with a future temporal orientation or future-oriented functions (i.e., planning, reevaluation of situation, and decision making; Stawarczyk et al., 2013; Stawarczyk, Majerus, Maj, et al., 2011) differed from other mindwandering episodes. We replicated the finding that most mind-wandering episodes were future-oriented (44\% of episodes versus $22 \%$ oriented towards the past, $15 \%$ towards the present, and $19 \%$ with no precise temporal orientation). However, sleepiness did not vary between future and non-future mind-wandering episodes $[b=-0.02(S E=0.07)$; LR $(1 \mathrm{df})=$ $.14 ; p=.71]$. Concerning their attributed functions, we also replicated the findings that mindwandering episodes had mostly future-oriented functions (49\% of episodes versus $20 \%$ with other functions and $31 \%$ with no attributed function). Only 18 of the 409 episodes (4.4\%) were rated as attempts to maintain arousal. Mind-wandering episodes with future-oriented functions did not differ from other episodes in terms of associated somnolence $[b=0.01$ ( $S E$ $=0.06) ; \operatorname{LR}(1 \mathrm{df})=0.02 ; p=.89]$.

Results of the analyses for the phenomenological dimensions rated on Likert-scales can be seen in Table 7. At a descriptive level, we replicated the findings that most mindwandering episodes involved moderate amount of inner speech and mental imagery, were generally not intended, did not belong to highly structured sequences of thoughts, and were not thoughts that occur repetitively in daily life. In addition, the content of the episodes was highly realistic, moderately important, and mostly emotionally neutral, although showing a slight positive bias (for similar results, see Stawarczyk et al., 2013; Stawarczyk, Majerus, 
Maj, et al., 2011). None of these phenomenological dimensions varied according to sleepiness level. Together, these results suggest that sleepiness had no influence on the phenomenological features of mind-wandering episodes.

\section{Discussion}

The purpose of the present study was to investigate the relationships between mindwandering and sleepiness, as well as their respective influences on task performance. More specifically, we sought to determine whether mind-wandering and sleepiness have distinguishable effects on task performance at the between- and within-individual levels. These questions were investigated using online experience sampling measures of sleepiness and mind-wandering frequency while the participants performed the Sustained Attention to Response Task (SART; Robertson et al., 1997), and questionnaires assessing mind-wandering and sleep-related disturbances in daily life were also administered.

In line with previous observations (e.g., Carciofo et al., 2014; McVay et al., 2009; Ottaviani et al., 2013), we found that mind-wandering and sleepiness were frequently cooccurring. At the between-participants level, both online measures of mind-wandering and sleepiness during the SART, as well as measures of mind-wandering and sleep-related disturbances in daily life were significantly related. At the within-participant level, mindwandering reports during the SART were associated with increased sleepiness compared to being focused on-task. Furthermore, we found that some of the explained variance in SART performance (as indexed by target accuracy and the variability of RTs) was shared by mindwandering and sleepiness. These results confirm that mind-wandering and sleepiness are frequently co-occurring and suggest that these two phenomena might be partially underlain by common mechanisms. Importantly, however, mind-wandering and sleepiness also had distinguishable effects on SART performance. Specifically, at both the within- and between- 
participant levels, sleepiness and mind-wandering both uniquely contributed to the prediction of commission errors and variability in RTs, suggesting that these two phenomena have an additive deleterious impact on task performance. Furthermore, regarding mean RTs, we found, at the within-participants level, that mind-wandering and sleepiness had opposite effects: sleepiness was associated with shorter RTs for non-targets, whereas mind-wandering was associated with longer RTs. Together, these latter findings suggests that sleepiness and mind-wandering episodes impact SART performance, in part, through distinct and nonoverlapping mechanisms.

A possible explanation for the frequent co-occurrence of mind-wandering and sleepiness and their shared influence on SART performance might stem from a decrease in attentional control abilities. There is evidence that, during periods of increased sleepiness (e.g., resulting from sleep deprivation), top-down attentional control processes supported by the fronto-parietal regions of the brain and involved in maintaining a sustained task-related focus are impaired (e.g., Goel, Rao, Durmer, \& Dinges, 2009; Lim \& Dinges, 2010; Tucker et al., 2011). Furthermore, recent theories suggest that mind-wandering often begins because of a loosening of attentional control processes involved in maintaining attention towards the task at hand, resulting in the intrusion of self-generated thoughts in consciousness (e.g., Smallwood, 2013; Thomson, Besner, \& Smilek, 2015). Therefore, it could be that increased sleepiness is associated with reduced attentional control abilities, resulting in impaired task performance and favoring the appearance of mind-wandering. Thus, sleepiness and mindwandering might share some of the explained variance in SART performance because of associated decreases in attentional control abilities. To further test this possibility, it would be interesting in future research to investigate whether the association between mind-wandering and sleepiness is mediated by measures of attentional control abilities, such as working memory capacity (Engle \& Kane, 2004; Kane, Conway, Hambrick, \& Engle, 2007). 
Beyond its shared influence with sleepiness, mind-wandering also uniquely contributed to the prediction of SART performance. This suggests that the effect of mindwandering on task performance is not entirely explained by decreases in attentional control abilities. Indeed, a recent study showed that mind-wandering was a significant predictor of target accuracy and RT variability during the SART, above and beyond a composite measure of attentional control abilities (Stawarczyk et al., 2014). It has recently been proposed that once mind-wandering episodes enter consciousness (in part due to temporally failures in attentional control abilities), they consume cognitive resources, resulting in a state of perceptual decoupling from immediate sensory inputs (Schooler et al., 2011; Smallwood \& Schooler, 2015), which further decreases the amount of resources normally devoted to the task at hand (Smallwood, 2013; Thomson et al., 2015). Evidence for the perceptual decoupling theory notably comes from physiological data showing that participants who experience more frequent mind-wandering during task performance show diminished cortical EEG responses to the presentation of task-irrelevant stimuli (Barron, Riby, Greer, \& Smallwood, 2011; Kam \& Handy, 2013). This proposal can also explain the slowing of RTs that was specifically associated with mind-wandering reports in the present study (at the within-participant level). A recent EEG study indeed suggest that longer RTs during mindwandering compared to on-task focus are not only associated with disrupted sensory processing of task stimuli, but also with the need of engaging additional neural resources to recouple attention to the task at hand when producing responses (Baird, Smallwood, Lutz, \& Schooler, 2014).

Overall, it could thus be that increased sleepiness is associated with reduced attentional control abilities, resulting in an initial decrease in task performance and favoring the appearance of mind-wandering, which in turn further impacts task performance through perceptual decoupling. Although this proposal remains to be investigated in detail, it is in line 
with the results of recent neuroimaging studies (e.g., Chee \& Chuah, 2007; De Havas, Parimal, Soon, \& Chee, 2012; Drummond et al., 2005; Maire et al., 2015) showing that performance decreases resulting from sleep deprivation are not only associated with reduced activity in frontoparietal regions supporting attentional control processes, but also with increased activity in the default network, a set of brain areas which has consistently been associated with mind-wandering (for a meta-analyses on the neural correlates of mindwandering, see Fox, Spreng, Ellamil, Andrews-Hanna, \& Christoff, 2015; Stawarczyk \& D'Argembeau, 2015).

A somewhat surprising finding was that mind-wandering and sleepiness had opposite effects on mean RTs to the non-targets during the SART. It is important to note, however, that both longer and shorter RTs are related to poorer accuracy while performing the SART, and are considered to reflect attentional lapses (McVay \& Kane, 2012). Slow and fast RTs are thought to represent distinct forms of task disengagement (Cheyne, Solman, Carriere, \& Smilek, 2009), and it has more specifically been proposed that speeding of RTs during the SART reflect the shifting to a mindless and inconsistent style of responding where participants emit automatic motor responses before complete stimulus processing (Manly, Robertson, Galloway, \& Hawkins, 1999; Robertson et al., 1997). Our findings suggest that this kind of mindless and fast responses during SART performance may be particularly associated with sleepiness (see also Bloomfield, Espie, \& Evans, 2010). Thus, whereas mindwandering might specifically impair performance because of perceptual decoupling (Schooler et al., 2011; Smallwood \& Schooler, 2015; Stawarczyk et al., 2014), sleepiness might rather be associated with an impulsive style of response during the SART. Perceptual decoupling and impulsive responding would have additive deleterious effects on target accuracy and variability of RTs, but opposite effects on mean RTs. 
Besides mind-wandering, a second category of thought-probe responses whose frequency was also related to higher sleepiness during the SART were absences (or mindblanking). In addition, we found, at the within-participant level, that absences were associated with lower target accuracy and with higher levels of sleepiness than mind-wandering. These results are in line with the few previous studies suggesting that mind-blanking is distinguishable from mind-wandering and could represent an extreme case of perceptual decoupling where attention fails to bring any stimuli into conscious awareness (e.g., Schooler et al., 2004; Ward \& Wegner, 2013). Given their association with the highest levels of sleepiness during the SART, it could be that absences correspond to the short periods of microsleep that often occur during extended and monotonous tasks, even in normally rested individuals (e.g., Poudel, Innes, Bones, \& Jones, 2010; Poudel, Innes, Bones, Watts, \& Jones, 2014). The study of mind-blanking is still in its infancy, however, and our results must be considered with caution because absences were the least frequent kind of thought probe reports (only 92 responses of this type were made by the 95 participants), and they were not related to sleep-disturbances in the past month (which may suggest that they are highly influenced by situational variables). Future studies should be conducted to more specifically assess the specific features of absences, as well as their relationships with sleepiness during task performance. If mind-blanking truly represents short microsleep intervals where attention fails to bring any stimuli into consciousness, then it should increase following procedures that increase daytime sleepiness (e.g., sleep deprivation or restriction periods).

Finally, it is important to note that, due to the design of the present study, no direct causal interpretations can be drawn from our results regarding the possible interplay between the occurrence of sleepiness and mind-wandering. It can nonetheless be noted that several previous studies have shown that the presence of mind-wandering-like thoughts during the day (e.g., Ottaviani \& Couyoumdjian, 2013; Takano, Ueno, \& Tanno, 2014) and prior to sleep 
(e.g., Baker et al., 2015; Wicklow \& Espie, 2000) can predict difficulties of sleep-onset and a decrease of the physiological de-arousal generally associated with normal sleep processes (see also Marques, Gomes, Clemente, Moutinho dos Santos, \& Castelo-Branco, 2015). Similarly, other laboratory studies have shown that the occurrence of mind-wandering is generally associated with increased sympathetic arousal, such as heart rate and skin conductance (for a review, see Smallwood \& Schooler, 2006). Thus, although mind-wandering episodes are associated with increased sleepiness at the moment of their occurrence, it could be that they nonetheless induce a state of increased cognitive and physiological arousal associated with sleep difficulties. In the present research, only $4 \%$ of mind-wandering episodes were rated as explicit attempts to stay awake, and future studies using experience sampling methods should more specifically investigate (for instance with time-lag analyses) whether the presence of mind-wandering and absences at a time $t$ can predict higher/lower sleepiness at time $t+1$ (for similar analyses on the relationship between mind-wandering and affect, see Killingsworth \& Gilbert, 2010; Ruby, Smallwood, Engen, \& Singer, 2013).

To conclude, this study is one the first attempt to bridge the gap between the mindwandering and sleepiness areas of research, two domains sharing striking similarities in their effects on daily life activities and task performance but whose interaction has been mostly overlooked thus far. As expected, we found that mind-wandering and sleepiness disturbances are frequently co-occurring. Most importantly, however, our results also revealed that these two phenomena are distinguishable in terms of their relationships with task performance. These novel findings indicate the necessity to consider mind-wandering and sleepiness as distinct yet related attentional sates. Future studies interested in either of these two phenomena would greatly benefit from conjointly assessing them in order to obtain purer estimations of their respective impact on cognitive functioning. 


\section{References}

Akerstedt, T., \& Gillberg, M. (1990). Subjective and objective sleepiness in the active individual. International Journal of Neuroscience, 52(1-2), 29-37. doi: http://dx.doi.org/10.3109/00207459008994241

Andrews-Hanna, J. R., Reidler, J. S., Huang, C., \& Buckner, R. L. (2010). Evidence for the default network's role in spontaneous cognition. Journal of Neurophysiology, 104(1), 322-335. doi: http://dx.doi.org/10.1152/jn.00830.2009

Baird, B., Smallwood, J., Lutz, A., \& Schooler, J. W. (2014). The Decoupled Mind: Mindwandering Disrupts Cortical Phase-locking to Perceptual Events. Journal of Cognitive Neuroscience, 26(11), 2596-2607. doi: http://dx.doi.org/10.1162/jocn_a_00656

Baird, B., Smallwood, J., Mrazek, M. D., Kam, J. W. Y., Franklin, M. S., \& Schooler, J. W. (2012). Inspired by distraction: Mind wandering facilitates creative incubation. Psychological $\quad$ Science, $\quad$ 23(10), d17-1122. doi: http://dx.doi.org/10.1177/0956797612446024

Baird, B., Smallwood, J., \& Schooler, J. W. (2011). Back to the future: Autobiographical planning and the functionality of mind-wandering. Consciousness \& Cognition, 20(4), 1604-1611. doi: http://dx.doi.org/10.1016/j.concog.2011.08.007

Baker, L. D., Baldwin, D. S., \& Garner, M. (2015). Daytime intrusive thoughts and subjective insomnia symptoms. Psychiatry Research, 229(3), 1038-1042. doi: http://dx.doi.org/10.1016/j.psychres.2015.02.022

Barron, E., Riby, L. M., Greer, J., \& Smallwood, J. (2011). Absorbed in thought: the effect of mind wandering on the processing of relevant and irrelevant events. Psychological Science, 22(5), 596-601. doi: http://dx.doi.org/10.1177/0956797611404083

Bernhardt, B. C., Smallwood, J., Tusche, A., Ruby, F. J., Engen, H. G., Steinbeis, N., \& Singer, T. (2014). Medial prefrontal and anterior cingulate cortical thickness predicts 
shared individual differences in self-generated thought and temporal discounting. Neuroimage, 90, 290-297. doi: http://dx.doi.org/10.1016/j.neuroimage.2013.12.040

Blais, F. C., Gendron, L., Mimeault, V., \& Morin, C. M. (1997). Evaluation de l'insomnie: validation de trois questionnaires [Evaluation of insomnia: validity of 3 questionnaires]. L'Encéphale, 23(6), 447-453.

Bloomfield, I. L., Espie, C. A., \& Evans, J. J. (2010). Do sleep difficulties exacerbate deficits in sustained attention following traumatic brain injury? Journal of the International Neuropsychological Society, 16(1), 17-25. doi: http://dx.doi.org/10.1017/S1355617709990798

Bonnefond, A., Doignon-Camus, N., Touzalin-Chretien, P., \& Dufour, A. (2010). Vigilance and intrinsic maintenance of alert state: An ERP study. Behavioural Brain Research, 211(2), 185-190. doi: http://dx.doi.org/10.1016/j.bbr.2010.03.030

Callard, F., Smallwood, J., Golchert, J., \& Margulies, D. S. (2013). The era of the wandering mind? Twenty-first century research on self-generated mental activity. Frontiers in Psychology, 4, 891. doi: http://dx.doi.org/10.3389/fpsyg.2013.00891

Carciofo, R., Du, F., Song, N., \& Zhang, K. (2014). Mind wandering, sleep quality, affect and chronotype: an exploratory study. PLoS ONE [Electronic Resource], 9(3), e91285. doi: http://dx.doi.org/10.1371/journal.pone.0091285

Casner, S. M., \& Schooler, J. W. (2014). Thoughts in flight: automation use and pilots' taskrelated and task-unrelated thought. Human Factors, 56(3), 433-442. doi: http://dx.doi.org/10.1177/0018720813501550

Casner, S. M., \& Schooler, J. W. (2015). Vigilance impossible: Diligence, distraction, and daydreaming all lead to failures in a practical monitoring task. Consciousness \& Cognition, 35, 33-41. doi: http://dx.doi.org/10.1016/j.concog.2015.04.019 
Chee, M. W., \& Chuah, Y. M. (2007). Functional neuroimaging and behavioral correlates of capacity decline in visual short-term memory after sleep deprivation. Proceedings of the National Academy of Sciences of the United States of America, 104(22), 94879492. doi: http://dx.doi.org/10.1073/pnas.0610712104

Cheyne, J. A., Solman, G. J. F., Carriere, J. S. A., \& Smilek, D. (2009). Anatomy of an error: A bidirectional state model of task engagement/disengagement and attention-related errors. $\quad$ Cognition, $\quad$ 111(1), 98-113. doi: http://dx.doi.org/10.1016/j.cognition.2008.12.009

Christoff, K., Gordon, A. M., Smallwood, J., Schooler, J. W., \& Smith, R. (2009). Experience sampling during fMRI reveals default network and executive system contributions to mind wandering. Proceedings of the National Academy of Sciences of the United States of $\quad$ America, $\quad$ 106(21), http://dx.doi.org/10.1073/pnas.0900234106

Connor, J., Norton, R., Ameratunga, S., Robinson, E., Civil, I., Dunn, R., . . . Jackson, R. (2002). Driver sleepiness and risk of serious injury to car occupants: population based case control study. $\quad B M J, \quad 324(7346), \quad 1125 . \quad$ doi: http://dx.doi.org/10.1136/bmj.324.7346.1125

Curcio, G., Ferrara, M., \& De Gennaro, L. (2006). Sleep loss, learning capacity and academic performance. Sleep Medicine Reviews, 10(5), 323-337. doi: http://dx.doi.org/10.1016/j.smrv.2005.11.001

De Havas, J. A., Parimal, S., Soon, C. S., \& Chee, M. W. (2012). Sleep deprivation reduces default mode network connectivity and anti-correlation during rest and task performance. $\quad$ Neuroimage, $\quad$ 59(2), 1745-1751. doi: http://dx.doi.org/10.1016/j.neuroimage.2011.08.026 
Drummond, S. P. A., Bischoff-Grethe, A., Dinges, D. F., Ayalon, L., Mednick, S. C., \& Meloy, M. J. (2005). The neural basis of the psychomotor vigilance task. Sleep, 28(9), 1059-1068.

Engle, R. W., \& Kane, M. J. (2004). Executive Attention, Working Memory Capacity, and a Two-Factor Theory of Cognitive Control. In B. H. Ross (Ed.), The psychology of learning and motivation: Advances in research and theory, Vol 44 (pp. 145-199). New York, NY: Elsevier Science; US.

Farley, J., Risko, E. F., \& Kingstone, A. (2013). Everyday attention and lecture retention: the effects of time, fidgeting, and mind wandering. Frontiers in Psychology, 4, 619. doi: http://dx.doi.org/10.3389/fpsyg.2013.00619

Faul, F., Erdfelder, E., Lang, A. G., \& Buchner, A. (2007). G Power 3: a flexible statistical power analysis program for the social, behavioral, and biomedical sciences. Behavior Research Methods, 39(2), 175-191. doi: http://dx.doi.org/10.3758/BF03193146

Ford, E. S., Cunningham, T. J., Giles, W. H., \& Croft, J. B. (2015). Trends in insomnia and excessive daytime sleepiness among U.S. adults from 2002 to 2012. Sleep Medicine, 16(3), 372-378. doi: http://dx.doi.org/10.1016/j.sleep.2014.12.008

Fox, K. C., Spreng, R. N., Ellamil, M., Andrews-Hanna, J. R., \& Christoff, K. (2015). The wandering brain: Meta-analysis of functional neuroimaging studies of mindwandering and related spontaneous thought processes. Neuroimage, 111, 611-621. doi: http://dx.doi.org/10.1016/j.neuroimage.2015.02.039

Gabel, V., Maire, M., Reichert, C. F., Chellappa, S. L., Schmidt, C., Hommes, V., . . . Cajochen, C. (2013). Effects of artificial dawn and morning blue light on daytime cognitive performance, well-being, cortisol and melatonin levels. Chronobiology International, 30(8), 988-997. doi: http://dx.doi.org/10.3109/07420528.2013.793196 
Galera, C., Orriols, L., M'Bailara, K., Laborey, M., Contrand, B., Ribereau-Gayon, R., .. . Lagarde, E. (2012). Mind wandering and driving: responsibility case-control study. BMJ, 345, e8105. doi: http://dx.doi.org/10.1136/bmj.e8105

Garbarino, S., Nobili, L., Beelke, M., De Carli, F., \& Ferrillo, F. (2001). The contributing role of sleepiness in highway vehicle accidents. Sleep: Journal of Sleep Research \& Sleep Medicine, 24(2), 203-206.

Gaultney, J. F. (2010). The prevalence of sleep disorders in college students: impact on academic performance. Journal of American College Health, 59(2), 91-97. doi: http://dx.doi.org/10.1080/07448481.2010.483708

Goel, N., Rao, H., Durmer, J. S., \& Dinges, D. F. (2009). Neurocognitive Consequences of Sleep Deprivation. Seminars in Neurology Clinical Sleep Neurology, 29(4), 320-339. doi: http://dx.doi.org/10.1055/s-0029-1237117

Gomes, A. A., Tavares, J., \& de Azevedo, M. H. (2011). Sleep and academic performance in undergraduates: a multi-measure, multi-predictor approach. Chronobiology International, 28(9), 786-801. doi: http://dx.doi.org/10.3109/07420528.2011.606518

Green, S. B. (1991). How Many Subjects Does It Take To Do A Regression Analysis. Multivariate Behavioral Research, 26(3), 499-510. doi: http://dx.doi.org/10.1207/s15327906mbr2603_7

Harrison, Y., Jones, K., \& Waterhouse, J. (2007). The influence of time awake and circadian rhythm upon performance on a frontal lobe task. Neuropsychologia, 45(8), 1966-1972. doi: http://dx.doi.org/10.1016/j.neuropsychologia.2006.12.012

He, J., Becic, E., Lee, Y.-C., \& McCarley, J. S. (2011). Mind wandering behind the wheel: performance and oculomotor correlates. Human Factors, 53(1), 13-21. doi: http://dx.doi.org/10.1177/0018720810391530 
Helton, W. S. (2009). Impulsive responding and the sustained attention to response task. Journal of Clinical and Experimental Neuropsychology, 31(1), 39-47. doi: http://dx.doi.org/10.1080/13803390801978856

Helton, W. S., Kern, R. P., \& Walker, D. R. (2009). Conscious thought and the sustained attention to response task. Consciousness and Cognition: An International Journal, 18(3), 600-607. doi: http://dx.doi.org/10.1016/j.concog.2009.06.002

Henriquez, R. A., Chica, A. B., Billeke, P., \& Bartolomeo, P. (2016). Fluctuating Minds: Spontaneous Psychophysical Variability during Mind-Wandering. PLoS ONE [Electronic Resource], $\quad$ 11(2), e0147174. doi: http://dx.doi.org/10.1371/journal.pone.0147174

Hershner, S. D., \& Chervin, R. D. (2014). Causes and consequences of sleepiness among college students. Nature \& Science of Sleep, 6, 73-84. doi: http://dx.doi.org/10.2147/NSS.S62907

Hox, J. J. (2010). Multilevel analysis: Techniques and applications (2n Ed.). New York, NY: Routledge.

Jackson, M. L., \& Van Dongen, H. P. A. (2011). Cognitive effects of sleepiness. In M. J. Thorpy \& M. Billiard (Eds.), Sleepiness (pp. 72-81). Cambridge, UK Cambridge University Press.

Kaida, K., Akerstedt, T., Kecklund, G., Nilsson, J. P., \& Axelsson, J. (2007a). The effects of asking for verbal ratings of sleepiness on sleepiness and its masking effects on performance. Clinical Neurophysiology, 118(6), 1324-1331. doi: http://dx.doi.org/10.1016/j.clinph.2007.03.004

Kaida, K., Akerstedt, T., Kecklund, G., Nilsson, J. P., \& Axelsson, J. (2007b). Use of subjective and physiological indicators of sleepiness to predict performance during a 
vigilance task. Industrial Health, 45(4), 520-526. doi: http://doi.org/10.2486/indhealth.45.520

Kaida, K., Takahashi, M., Akerstedt, T., Nakata, A., Otsuka, Y., Haratani, T., \& Fukasawa, K. (2006). Validation of the Karolinska sleepiness scale against performance and EEG variables. Clinical Neurophysiology, 117(7), 1574-1581. doi: http://doi.org/10.1016/j.clinph.2006.03.011

Kam, J. W., \& Handy, T. C. (2013). The neurocognitive consequences of the wandering mind: a mechanistic account of sensory-motor decoupling. Frontiers in Psychology, 4, 725. doi: http://doi.org/10.3389/fpsyg.2013.00725

Kane, M. J., Brown, L. H., McVay, J. C., Silvia, P. J., Myin-Germeys, I., \& Kwapil, T. R. (2007). For whom the mind wanders, and when: An experience-sampling study of working memory and executive control in daily life. Psychological Science, 18(7), 614-621. doi: http://dx.doi.org/10.1111/j.1467-9280.2007.01948.x

Kane, M. J., Conway, A. R. A., Hambrick, D. Z., \& Engle, R. W. (2007). Variation in working memory capacity as variation in executive attention and control. In A. R. A. Conway, C. Jarrold, M. J. Kane, A. Miyake \& J. N. Towse (Eds.), Variation in working memory (pp. 21-46). New York, NY: Oxford University Press; US.

Killgore, W. D. (2010). Effects of sleep deprivation on cognition. Progress in Brain Research, 185, 105-129. doi: http://dx.doi.org/10.1016/B978-0-444-53702-7.00007-5

Killingsworth, M. A., \& Gilbert, D. T. (2010). A wandering mind is an unhappy mind. Science, 330(6006), 932. doi: http://dx.doi.org/10.1126/science.1192439

Lim, J., \& Dinges, D. F. (2008). Sleep deprivation and vigilant attention. Annals of the New York Academy of $\quad$ Sciences, 1129, 305-322. doi: http://dx.doi.org/10.1196/annals.1417.002 
Lim, J., \& Dinges, D. F. (2010). A meta-analysis of the impact of short-term sleep deprivation on cognitive variables. Psychological Bulletin, 136(3), 375-389. doi: http://dx.doi.org/10.1037/a0018883

Lindquist, S. I., \& McLean, J. P. (2011). Daydreaming and its correlates in an educational environment. Learning and Individual Differences, 21, 158-167. doi: http://dx.doi.org/10.1016/j.lindif.2010.12.006

Lo, J. C., Groeger, J. A., Santhi, N., Arbon, E. L., Lazar, A. S., Hasan, S., . . Dijk, D. J. (2012). Effects of partial and acute total sleep deprivation on performance across cognitive domains, individuals and circadian phase. PLoS ONE [Electronic Resource], 7(9), e45987. doi: http://dx.doi.org/10.1371/journal.pone.0045987

Lund, H. G., Reider, B. D., Whiting, A. B., \& Prichard, J. R. (2010). Sleep patterns and predictors of disturbed sleep in a large population of college students. Journal of Adolescent Health, 46(2), 124-132. doi: http://dx.doi.org/10.1016/j.jadohealth.2009.06.016

Maas, C. J., \& Hox, J. J. (2005). Sufficient Sample Sizes for Multilevel Modeling. Methodology: European Journal of Research Methods for the Behavioral and Social Sciences, 1(3), 86-92. doi: http://dx.doi.org/10.1027/1614-2241.1.3.86

MacLean, A. W., Davies, D. R., \& Thiele, K. (2003). The hazards and prevention of driving while sleepy. Sleep Medicine Reviews, 7(6), 507-521. doi: http://dx.doi.org/10.1016/S1087-0792(03)90004-9

Maillet, D., \& Rajah, M. N. (2013). Age-related changes in frequency of mind-wandering and task-related interferences during memory encoding and their impact on retrieval. Memory, 21(7), 818-831. doi: http://dx.doi.org/10.1080/09658211.2012.761714 
Maire, M., Reichert, C. F., Gabel, V., Viola, A. U., Phillips, C., Krebs, J., . . Schmidt, C. (2015). Fighting sleep at night: Brain correlates and vulnerability to sleep loss. Annals of Neurology, Advance online publication. doi: http://dx.doi.org/10.1002/ana.24434

Manly, T., Robertson, I. H., Galloway, M., \& Hawkins, K. (1999). The absent mind: further investigations of sustained attention to response. Neuropsychologia, 37(6), 661-670. doi: http://dx.doi.org/10.1016/S0028-3932(98)00127-4

Marques, D. R., Gomes, A. A., Clemente, V., Moutinho dos Santos, J., \& Castelo-Branco, M. (2015). Default-mode network activity and its role in comprehension and management of psychophysiological insomnia: A new perspective. New Ideas in Psychology, 36, 30-37. doi: http://dx.doi.org/10.1016/j.newideapsych.2014.08.001

Mason, M. F., \& Reinholtz, N. (2015). Avenues Down Which a Self-Reminding Mind Can Wander. Motivation Science, 1(1), 1-21. doi: http://dx.doi.org/10.1037/mot0000011

McVay, J. C., \& Kane, M. J. (2009). Conducting the train of thought: Working memory capacity, goal neglect, and mind wandering in an executive-control task. Journal of experimental psychology. Learning, memory, and cognition, 35(1), 196-204. doi: http://dx.doi.org/10.1037/a0014104

McVay, J. C., \& Kane, M. J. (2012). Drifting from slow to "d'oh!": Working memory capacity and mind wandering predict extreme reaction times and executive control errors. Journal of Experimental Psychology: Learning, Memory, \& Cognition, 38(3), 525-549. doi: http://dx.doi.org/10.1037/a0025896

McVay, J. C., Kane, M. J., \& Kwapil, T. R. (2009). Tracking the train of thought from the laboratory into everyday life: an experience-sampling study of mind wandering across controlled and ecological contexts. Psychonomic Bulletin \& Review, 16(5), 857-863. doi: http://dx.doi.org/10.3758/PBR.16.5.857 
Morin, C. M. (1993). Insomnia: Psychological assessment and management. New York: Guilford Press.

Mrazek, M. D., Franklin, M. S., Phillips, D. T., Baird, B., \& Schooler, J. W. (2013). Mindfulness Training Improves Working Memory Capacity and GRE Performance While Reducing Mind Wandering. Psychological Science, 24(5), 776-781. doi: http://dx.doi.org/10.1177/0956797612459659

Mrazek, M. D., Smallwood, J., Franklin, M. S., Chin, J. M., Baird, B., \& Schooler, J. W. (2012). The role of mind-wandering in measurements of general aptitude. Journal of Experimental Psychology: General, 141(4), 788-798. doi: http://dx.doi.org/10.1037/a0027968

Ottaviani, C., \& Couyoumdjian, A. (2013). Pros and cons of a wandering mind: a prospective study. Frontiers in Psychology, 4, 524. doi: http://dx.doi.org/10.3389/fpsyg.2013.00524

Ottaviani, C., Shapiro, D., \& Couyoumdjian, A. (2013). Flexibility as the key for somatic health: From mind wandering to perseverative cognition. Biological Psychology, 94(1), 38-43. doi: http://dx.doi.org/10.1016/j.biopsycho.2013.05.003

Poudel, G. R., Innes, C. R., Bones, P. J., \& Jones, R. D. (2010). The relationship between behavioural microsleeps, visuomotor performance and EEG theta. Conference Proceedings: ... Annual International Conference of the IEEE Engineering in Medicine \& Biology Society, 2010, 4452-4455. doi: http://dx.doi.org/10.1109/IEMBS.2010.5625956

Poudel, G. R., Innes, C. R., Bones, P. J., Watts, R., \& Jones, R. D. (2014). Losing the struggle to stay awake: divergent thalamic and cortical activity during microsleeps. Human Brain Mapping, 35(1), 257-269. doi: http://dx.doi.org/10.1002/hbm.22178 
Qu, W., Ge, Y., Xiong, Y., Carciofo, R., Zhao, W., \& Zhang, K. (2015). The relationship between mind wandering and dangerous driving behavior among Chinese drivers. Safety Science, 78, 41-48. doi: http://dx.doi.org/10.1016/j.ssci.2015.04.016

Randall, J. G., Oswald, F. L., \& Beier, M. E. (2014). Mind-wandering, cognition, and performance: a theory-driven meta-analysis of attention regulation. Psychological Bulletin, 140(6), 1411-1431. doi: http://dx.doi.org/10.1037/a0037428

Rasbash, J., Charlton, C., Browne, W. J., Healy, M., \& Cameron, B. (2009). MLwiN version 2.1. Centre for Multilevel Modelling, University of Bristol.

Risko, E. F., Anderson, N., Sarwal, A., Engelhardt, M., \& Kingstone, A. (2012). Everyday Attention: Variation in Mind Wandering and Memory in a Lecture. Applied Cognitive Psychology, 26(2), 234-242. doi: http://dx.doi.org/10.1002/acp.1814

Robertson, I. H., Manly, T., Andrade, J., Baddeley, B. T., \& Yiend, J. (1997). 'Oops!': performance correlates of everyday attentional failures in traumatic brain injured and normal subjects. Neuropsychologia, 35(6), 747-758. doi: http://dx.doi.org/10.1016/S0028-3932(97)00015-8

Ruby, F. J., Smallwood, J., Engen, H., \& Singer, T. (2013). How Self-Generated Thought Shapes Mood-The Relation between Mind-Wandering and Mood Depends on the Socio-Temporal Content of Thoughts. PLoS ONE [Electronic Resource], 8(10), e77554. doi: http://dx.doi.org/10.1371/journal.pone.0077554

Schooler, J. W., Reichle, E. D., \& Halpern, D. V. (2004). Zoning Out while Reading: Evidence for Dissociations between Experience and Metaconsciousness. In D. T. Levin (Ed.), Thinking and Seeing (pp. 203-226). Cambridge, MA: MIT Press.

Schooler, J. W., Smallwood, J., Christoff, K., Handy, T. C., Reichle, E. D., \& Sayette, M. A. (2011). Meta-awareness, perceptual decoupling and the wandering mind. Trends in Cognitive Sciences, 15(7), 319-326. doi: http://dx.doi.org/10.1016/j.tics.2011.05.006 
Seli, P., Cheyne, J. A., \& Smilek, D. (2012). Attention failures versus misplaced diligence: separating attention lapses from speed-accuracy trade-offs. Consciousness \& Cognition, 21(1), 277-291. doi: http://dx.doi.org/10.1016/j.concog.2011.09.017

Seli, P., Jonker, T. R., Cheyne, J. A., \& Smilek, D. (2013). Enhancing SART Validity by Statistically Controlling Speed-Accuracy Trade-Offs. Frontiers in Psychology, 4, 265. doi: http://dx.doi.org/10.3389/fpsyg.2013.00265

Short, M. A., \& Banks, S. (2014). The functional impact of sleep deprivation, sleep restriction, and sleep fragmentation. In M. T. Bianchi (Ed.), Sleep deprivation and disease: Effects on the body, brain and behavior (pp. 13-26). New York, NY: Springer Science + Business Media.

Singer, J. L. (1993). Experimental studies of ongoing conscious experience. Ciba Foundation Symposium, 174, 100-122. doi: http://dx.doi.org/10.1002/9780470514412.ch6

Singer, J. L., \& Antrobus, J. S. (1970). Imaginal process inventory. New York: City University of New York.

Singer, J. L., \& McCraven, V. G. (1961). Some characteristics of adult daydreaming. Journal of Psychology: Interdisciplinary and Applied, 51, 151-164. doi: http://dx.doi.org/10.1080/00223980.1961.9916467

Singer, J. L., \& Schonbar, R. A. (1961). Correlates of daydreaming: A dimension of selfawareness. Journal of consulting psychology, 25(1), 1-6. doi: http://dx.doi.org/10.1037/h0048906

Smallwood, J. (2011). Mind-wandering while reading: Attentional decoupling, mindless reading and the cascade model of inattention. Language and Linguistics Compass, 5(2), 63-77. doi: http://dx.doi.org/10.1111/j.1749-818X.2010.00263.x 
Smallwood, J. (2013). Distinguishing how from why the mind wanders: A process-occurrence framework for self-generated mental activity. Psychological Bulletin, 139(3), 519-535. doi: http://dx.doi.org/10.1037/a0030010

Smallwood, J., Baracaia, S. F., Lowe, M., \& Obonsawin, M. (2003). Task unrelated thought whilst encoding information. Consciousness and Cognition: An International Journal, 12(3), 452-484. doi: http://dx.doi.org/10.1016/S1053-8100\%2803\%2900018-7

Smallwood, J., Davies, J. B., Heim, D., Finnigan, F., Sudberry, M., O'Connor, R., \& Obonsawin, M. (2004). Subjective experience and the attentional lapse: Task engagement and disengagement during sustained attention. Consciousness and Cognition: An International Journal, 13(4), 657-690. doi: http://dx.doi.org/10.1016/j.concog.2004.06.003

Smallwood, J., Ruby, F. J., \& Singer, T. (2013). Letting go of the present: Mind-wandering is associated with reduced delay discounting. Consciousness \& Cognition, 22(1), 1-7. doi: http://dx.doi.org/10.1016/j.concog.2012.10.007

Smallwood, J., \& Schooler, J. W. (2006). The restless mind. Psychological Bulletin, 132(6), 946-958. doi: http://dx.doi.org/10.1037/0033-2909.132.6.946

Smallwood, J., \& Schooler, J. W. (2015). The science of mind wandering: empirically navigating the stream of consciousness. Annual Review of Psychology, 66, 487-518. doi: http://dx.doi.org/10.1146/annurev-psych-010814-015331

Song, X., \& Wang, X. (2012). Mind wandering in chinese daily lives - an experience sampling study. PLoS ONE [Electronic Resource], 7(9), e44423. doi: http://dx.doi.org/10.1371/journal.pone.0044423

Stawarczyk, D., Cassol, H., \& D'Argembeau, A. (2013). Phenomenology of future-oriented mind-wandering episodes. Frontiers in Psychology, 4, 225. doi: http://dx.doi.org/10.3389/fpsyg.2013.00425 
Stawarczyk, D., \& D'Argembeau, A. (2015). Neural correlates of personal goal processing during episodic future thinking and mind-wandering: An ALE meta-analysis. Human Brain Mapping, 36(8), 2928-2947. doi: http://dx.doi.org/10.1002/hbm.22818

Stawarczyk, D., Majerus, S., Catale, C., \& D'Argembeau, A. (2014). Relationships between mind-wandering and attentional control abilities in young adults and adolescents. Acta Psychologica, 148, 25-36. doi: http://dx.doi.org/10.1016/j.actpsy.2014.01.007

Stawarczyk, D., Majerus, S., Maj, M., Van der Linden, M., \& D'Argembeau, A. (2011). Mind-wandering: phenomenology and function as assessed with a novel experience sampling method. Acta Psychologica, 136(3), 370-381. doi: http://dx.doi.org/10.1016/j.actpsy.2011.01.002

Stawarczyk, D., Majerus, S., Maquet, P., \& D'Argembeau, A. (2011). Neural correlates of ongoing conscious experience: both task-unrelatedness and stimulus-independence are related to default network activity. PLoS ONE [Electronic Resource], 6(2), e16997. doi: http://dx.doi.org/10.1371/journal.pone.0016997

Stawarczyk, D., Majerus, S., Van der Linden, M., \& D'Argembeau, A. (2012). Using the daydreaming frequency scale to investigate the relationships between mindwandering, psychological well-being, and present-moment awareness. Frontiers in Psychology, 3, 363. doi: http://dx.doi.org/10.3389/fpsyg.2012.00363

Szpunar, K. K., Moulton, S. T., \& Schacter, D. L. (2013). Mind wandering and education: from the classroom to online learning. Frontiers in Psychology, 4, 495. doi: http://dx.doi.org/10.3389/fpsyg.2013.00495

Takano, K., Ueno, M., \& Tanno, Y. (2014). Self-focused thinking predicts nighttime physiological de-arousal. Biological Psychology, 97, 9-14. doi: http://dx.doi.org/10.1016/j.biopsycho.2014.01.001 
Taylor, D. J., Bramoweth, A. D., Grieser, E. A., Tatum, J. I., \& Roane, B. M. (2013). Epidemiology of insomnia in college students: relationship with mental health, quality of life, and substance use difficulties. Behavior Therapy, 44(3), 339-348. doi: http://dx.doi.org/10.1016/j.beth.2012.12.001

Thomson, D. R., Besner, D., \& Smilek, D. (2015). A Resource-Control Account of Sustained Attention: Evidence From Mind-Wandering and Vigilance Paradigms. Perspectives on $\begin{array}{llll}\text { Psychological } & \text { Science, } & \text { 10(1), } & \text { doi: }\end{array}$ http://dx.doi.org/10.1177/1745691614556681

Tucker, A. M., Rakitin, B. C., Basner, R. C., Gazes, Y., Steffener, J., \& Stern, Y. (2011). fMRI activation during failures to respond key to understanding performance changes with sleep deprivation. Behavioural Brain Research, 218(1), 73-79. doi: http://dx.doi.org/10.1016/j.bbr.2010.11.012

Unsworth, N., Brewer, G. A., \& Spillers, G. J. (2012). Variation in cognitive failures: An individual differences investigation of everyday attention and memory failures. Journal of Memory and Language, 67(1), 1-16. doi: http://dx.doi.org/10.1016/j.jml.2011.12.005

Unsworth, N., McMillan, B. D., Brewer, G. A., \& Spillers, G. J. (2012). Everyday attention failures: An individual differences investigation. Journal of Experimental Psychology: Learning, Memory, and Cognition, 38(6), 1765-1772. doi: http://dx.doi.org/10.1037/a0028075

Ward, A. F., \& Wegner, D. M. (2013). Mind-blanking: when the mind goes away. Frontiers in Psychology, 4, 650. doi: http://dx.doi.org/10.3389/fpsyg.2013.00650

Wicklow, A., \& Espie, C. (2000). Intrusive thoughts and their relationship to actigraphic measurement of sleep: Towards a cognitive model of insomnia. Behaviour Research 
and Therapy, 38(7), 679-693. doi: http://dx.doi.org/10.1016/S0005$7967 \% 2899 \% 2900136-9$

Yanko, M. R., \& Spalek, T. M. (2014). Driving with the wandering mind: the effect that mind-wandering has on driving performance. Human Factors, 56(2), 260-269. doi: http://dx.doi.org/10.1177/0018720813495280 


\section{Footnotes}

${ }^{1}$ It is important to note that, although SART performance is sensitive to the presence of mind-wandering, several studies have shown that inferences on thought content cannot be made unequivocally on the basis on task performance alone (i.e, not all errors can be predicted by the presence of mind-wandering and not all mind-wandering episodes are associated with decreased performance; see for instance Henriquez et al., 2016; McVay \& Kane, 2012). Thus, the behavioral consequences of mind-wandering should not be equated with the phenomenon itself (as is done in some studies) because there is no one-to-one correspondence between mind-wandering and indices of task performance. In our view, experience sampling procedures remain the gold standard to assess the occurrence of mindwandering during task performance.

${ }^{2}$ For completeness, we also computed the same regression model without entering mean RT as independent variable. Although this model was significant $\left[F(2,92)=3.68 ; p=.03 ; R^{2}\right.$ $=.07]$, neither mind-wandering reports $[t(92)=-1.60 ; p=.11 ; \beta=-.17 ; S E=.11]$ nor KSS scores $[t(92)=-1.60 ; p=.11 ; \beta=-.17 ; S E=.11]$ remained significant independent predictors of target accuracy. However, as mentioned in the main text, these latter results should be considered with caution because measures of SART accuracy that do not control for mean RTs are sensitive to deliberate speed-accuracy trade-offs.

${ }^{3}$ In addition, as the only study that examined how fluctuations in somnolence affect task performance at the within-individual level showed that reports of somnolence on the KSS can predict task performance over four minute periods (Kaida et al., 2007b), we also performed analyses on the mean and CV of RTs computed on the entire block rather than the last 10 seconds. The results of these latter analyses are similar to those obtained when analyzing the last four trials of each block (see the Supplemental Material for detailed results). 
Table 1: Between-participants correlation analyses and descriptive statistics

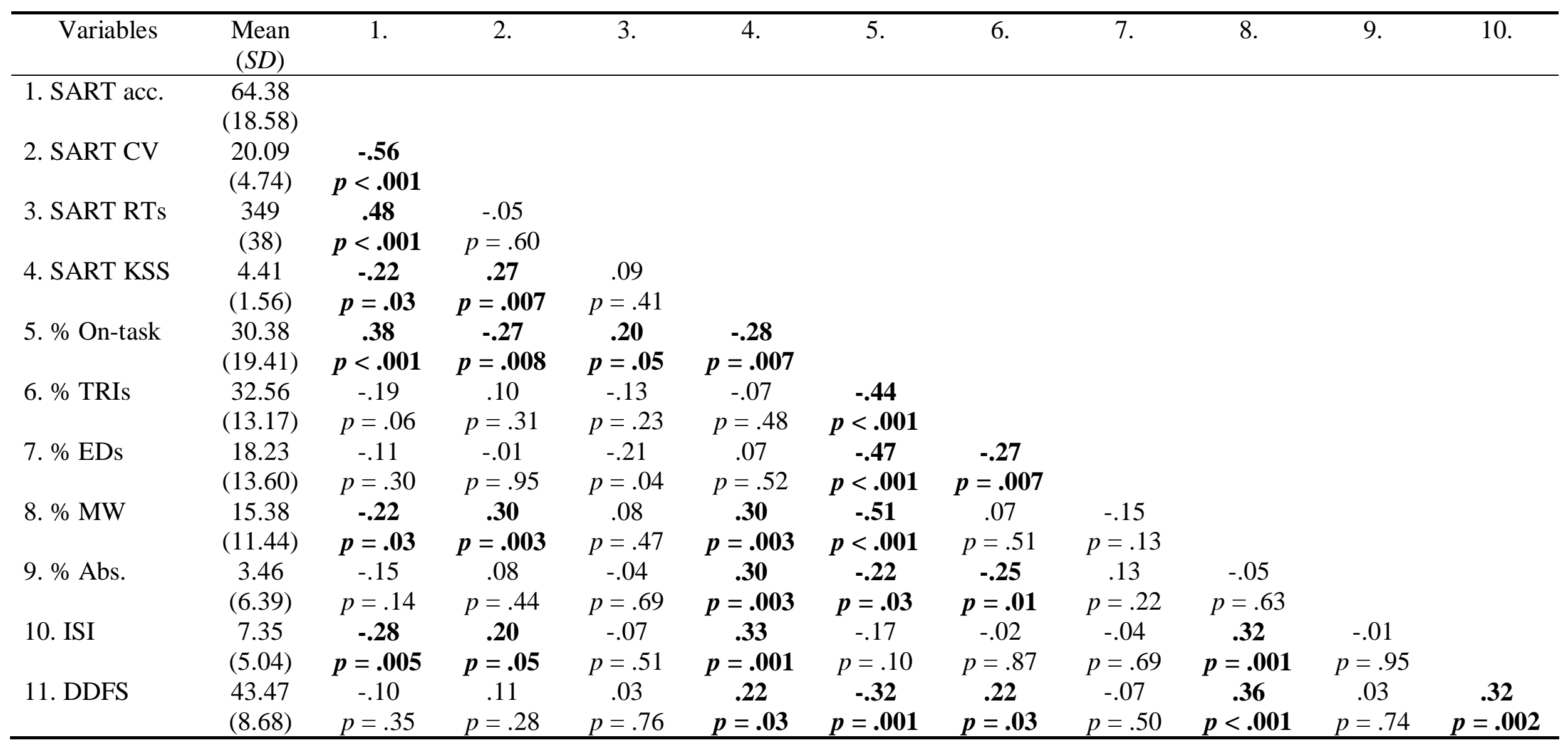

Note. SART acc. = accuracy to the target stimuli; SART CV = Coefficient of variation of RTs for the non-target stimuli; SART RTs $=$ mean RT for the non-target stimuli; SART KSS = mean score of the KSS administrations during the SART; TRIs = task-related interferences; EDs = external distractions; MW = mind-wandering; Abs. = absences; ISI = Insomnia Severity Index; DDFS = Daydreaming Frequency Scale. 
Table 2: Multiple regression analyses on SART performance at the between-participant level

a. Variability of RTs as dependent variable

\begin{tabular}{lcccc} 
& $\beta$ & $S E$ & $t(92)$ & $p$ \\
\cline { 2 - 5 } 1. KSS scores & .20 & .10 & 1.97 & $\mathbf{. 0 5}$ \\
2. Mind-wandering & .24 & .10 & 2.35 & $\mathbf{. 0 2}$
\end{tabular}

b. Target accuracy as dependent variable

\begin{tabular}{lcccc} 
& $\beta$ & $S E$ & $t(91)$ & $p$ \\
\cline { 2 - 5 } 1. Mean RTs & .52 & .09 & 6.04 & $<.001$ \\
2. KSS scores & -.20 & .09 & -2.28 & $\mathbf{. 0 2}$ \\
3. Mind-wandering & -.20 & .09 & -2.19 & $\mathbf{. 0 3}$ \\
\hline
\end{tabular}

Note. KSS scores $=$ mean score of the KSS administrations during the SART. 
Table 3: Relationship between degree of sleepiness and responses to the thought probes at the within-participants level

\begin{tabular}{lcc}
\hline Categories of thought-probes responses & $b(S E)$ & $p$ \\
\hline Task-related interferences & $0.72(0.07)$ & $<.001$ \\
External distractions & $1.18(0.08)$ & $<.001$ \\
Mind-wandering & $1.07(0.08)$ & $<.001$ \\
Absence & $1.95(0.15)$ & $<.001$ \\
\hline
\end{tabular}

Note. The coefficients represent contrasts with the reference category (being focused on-task). 
Table 4: Multilevel regression models predicting target accuracy per block from thought probe responses and sleepiness

\begin{tabular}{lcc}
\hline Variables & $b(S E)$ & $p$ \\
\hline Sleepiness & $-3.64(.45)$ & $<. \mathbf{0 0 1}$ \\
Task-related interferences & $-14.48(1.62)$ & $<. \mathbf{0 0 1}$ \\
External distractions & $-11.18(1.97)$ & $<.001$ \\
Mind-wandering & $-9.98(2.05)$ & $<. \mathbf{0 0 1}$ \\
Absence & $-17.39(3.70)$ & $<. \mathbf{0 0 1}$ \\
\hline
\end{tabular}

Note. The coefficients represent contrasts with the reference category (being focused on-task). 
Table 5: Multilevel regression models predicting RT variability for the last four stimuli of each block from thought probe responses and sleepiness

\begin{tabular}{lcc}
\hline Variables & $b(S E)$ & $p$ \\
\hline Sleepiness & $0.44(0.12)$ & $<.001$ \\
Task-related interferences & $1.28(0.45)$ & $\mathbf{. 0 0 5}$ \\
External distractions & $1.58(0.55)$ & $\mathbf{. 0 0 4}$ \\
Mind-wandering & $1.52(0.57)$ & $\mathbf{. 0 0 8}$ \\
Absence & $1.20(1.04)$ & .25 \\
\hline
\end{tabular}

Note. The coefficients represent contrasts with the reference category (being focused on-task). 
Table 6: Multilevel regression models predicting mean RTs for the last four stimuli of each block from thought probe responses and sleepiness

\begin{tabular}{lcc}
\hline Variables & $b(S E)$ & $p$ \\
\hline Sleepiness & $-3.18(0.69)$ & $<.001$ \\
Task-related interferences & $2.90(2.41)$ & .23 \\
External distractions & $6.32(2.94)$ & $\mathbf{. 0 3}$ \\
Mind-wandering & $7.66(3.06)$ & $\mathbf{. 0 1}$ \\
Absence & $6.18(5.50)$ & .26 \\
\hline
\end{tabular}

Note. The coefficients represent contrasts with the reference category (being focused on-task). 
Table 7: Effects of sleepiness on the phenomenological dimensions of mind-wandering

\begin{tabular}{lccccc}
\hline Phenomenological dimensions & $M$ & $S D$ & $b(S E)$ & LR (1 df) & $p$ \\
\hline Visual Imagery & 4.04 & 2.08 & $0.03(0.02)$ & 2.71 & .10 \\
Inner Speech & 4.07 & 2.18 & $-0.003(0.02)$ & 0.04 & .84 \\
Intended & 2.10 & 1.38 & $0.002(0.03)$ & 0.005 & .94 \\
Structured & 3.26 & 1.91 & $0.003(0.02)$ & 0.02 & .89 \\
Realism & 5.56 & 1.80 & $-0.01(0.02)$ & 0.34 & .56 \\
Importance & 3.82 & 2.04 & $-0.005(0.02)$ & 0.10 & .75 \\
Repetition & 2.85 & 1.99 & $-0.01(0.02)$ & 0.18 & .67 \\
Affective valence & 0.47 & 1.44 & $-0.01(0.02)$ & 0.10 & .75 \\
\hline
\end{tabular}

Note. All mean scores range from 1 to 7 except for the affective valence dimension the range of which goes from -3 to +3 . 
Figure 1: Increase in sleepiness with time on task.

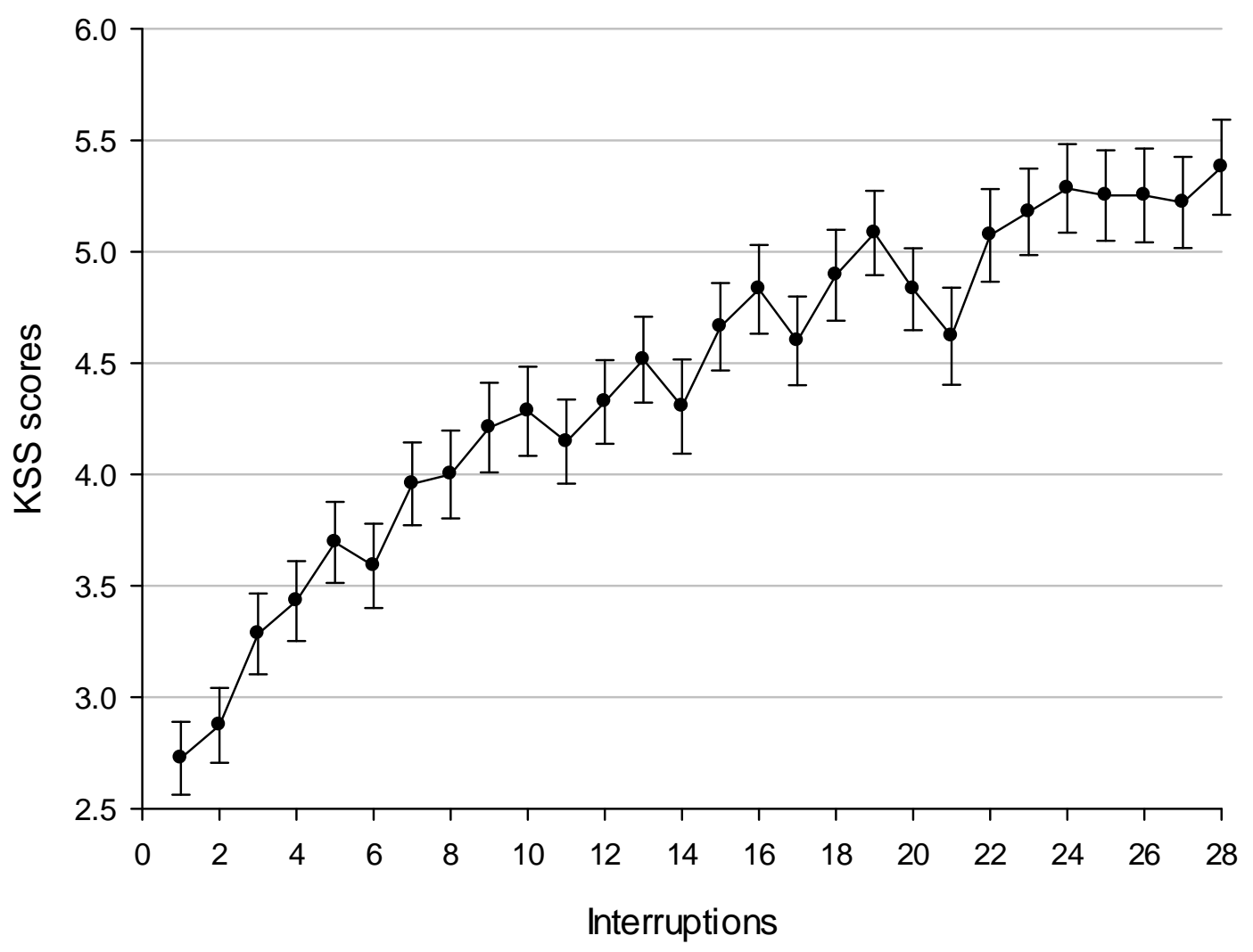

Figure 1. Error bars represent the standard errors of the means. KSS = Karolinska Sleepiness Scale. 
Figure 2: Differences in KSS scores according to the responses given to the thought probes

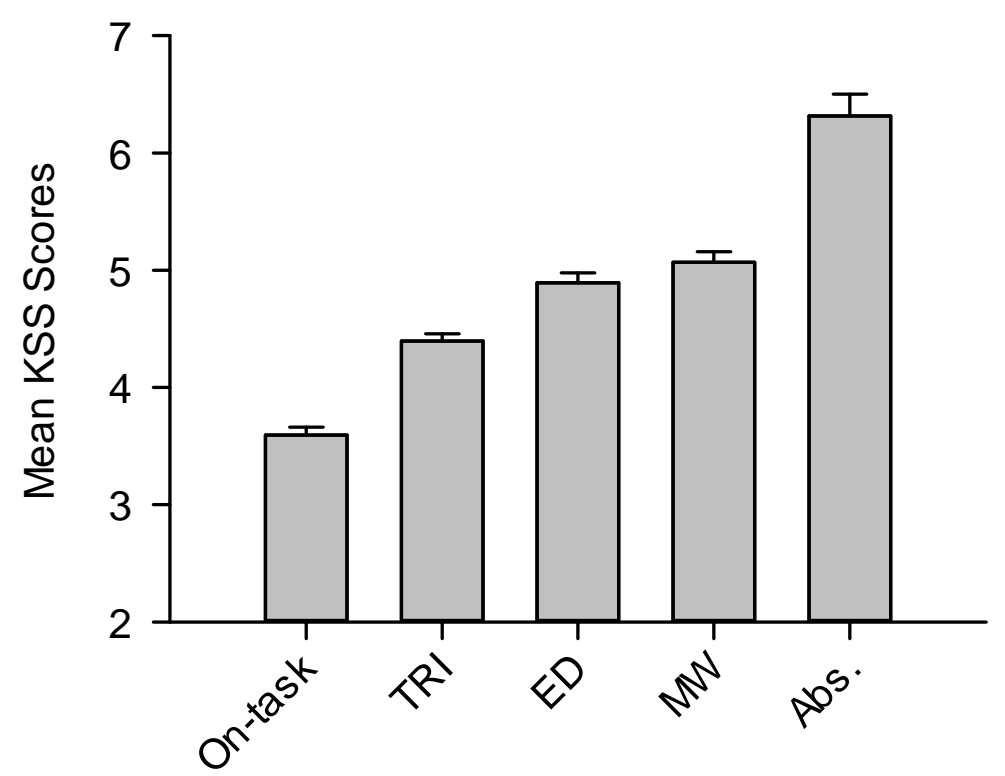

Figure 2. Error bars represent the standard errors of the means. KSS = Karolinska Sleepiness Scale; TRI = task-related interference ED = external distraction; $\mathrm{MW}=$ mind-wandering; Abs. = absence . 


\section{Supplemental Material}

\section{Variation of RTs in the whole block according to thought probe responses and sleepiness at the within-individual level}

When considering the variability of RTs for each block considered in its entirety, $75 \%$ of the total variance was due to within-participant differences. The LR test for the first model with sleepiness alone as independent variable indicated that RT variability was higher with increasing level of sleepiness $[b=0.46(S E=0.09) ; L R(1 \mathrm{df})=25.12 ; p<.001]$. The LR test for the model with sleepiness and thought probe responses considered simultaneously indicated that this second model explained a significantly larger part of the variance of RT variability than the model with sleepiness alone $[L R(1 \mathrm{df})=11.76 ; p<.001]$. The coefficients for sleepiness, task-related interference, external distractions, and mindwandering were significant in this second model (see Table S1), indicating that these different variables all have (at least partially) independent influences on RT variability to the nontarget stimuli of each block.

Table S1: Multilevel regression models predicting RT variability per block from thought probe responses and sleepiness

\begin{tabular}{lcc}
\hline & $b(S E)$ & $p$ \\
\hline Sleepiness & $0.36(0.01)$ & $<. \mathbf{0 0 1}$ \\
Task-related interferences & $0.70(0.35)$ & $\mathbf{. 0 4}$ \\
External distractions & $1.14(0.42)$ & $\mathbf{. 0 0 7}$ \\
Mind-wandering & $1.35(0.44)$ & $\mathbf{. 0 0 2}$ \\
Absence & $1.02(0.79)$ & .20 \\
\hline Note. The coefficients represent contrasts with the reference category (being focused on-task).
\end{tabular}


Concerning the mean RTs for each block considered in its entirety, 39\% of the total variance was due to within-participant differences. The LR test for the first model with sleepiness alone as independent variable indicated that RTs were faster with increasing level of sleepiness $[b=-3.64(S E=0.43) ; L R(1 \mathrm{df})=71.18 ; p<.001]$. The LR test for the model with sleepiness and thought probe responses considered simultaneously indicated that this second model explained a significantly larger part of the variance of mean RTs than the model with sleepiness only $[L R(1 \mathrm{df})=15.10 ; p<.001]$. Interestingly, in this last model, sleepiness remained associated with faster RTs, whereas mind-wandering and EDs were also significant predictors but were associated with slower RTs compared to being fully focused on task (see Table S2). These results suggest that mind-wandering and sleepiness have opposite effects on the speed of RTs to non-target stimuli during the SART at the withinparticipant level.

Table S2: Multilevel regression models predicting mean RTs per block from thought probe responses and sleepiness

\begin{tabular}{llc}
\hline & $b(S E)$ & $p$ \\
\hline Sleepiness & $-3.97(0.45)$ & $<.001$ \\
Task-related interferences & $1.92(1.56)$ & .22 \\
External distractions & $5.72(1.91)$ & $\mathbf{. 0 0 3}$ \\
Mind-wandering & $5.01(1.98)$ & $\mathbf{. 0 1}$ \\
Absence & $-2.84(3.56)$ & .42 \\
\hline Note. The coefficients represent contrasts with the reference category (being focused on-task).
\end{tabular}

